\title{
DISCURSO, INFORMAÇÃO E CONHECIMENTO: PERSPECTIVAS INICIAIS À CIÊNCIA DA INFORMAÇÃO
}

\author{
Discourse, Information and Knowledge: initial perspectives for information science
}

\section{Thiago Henrique Bragato Barros}

\author{
Professor Adjunto na Faculdade de Arquivologia e no Programa de Pós-Graduação em Ciência da Informação \\ Universidade Federal do Pará, thiagobarros@ufpa.br
}

\begin{abstract}
Resumo
Discute-se que a Ciência da Informação é compreendida como uma área interdisciplinar que possui características e metodologias próprias. A Análise do Discurso apresenta princípios teóricos e metodológicos que contribuem para a compreensão e delimitação de campos de pesquisa sóciocientíficos. Busca-se apresentar aspectos históricos e conceituais relacionados ao seu desenvolvimento metodológico, buscando demonstrar maneiras para demarcar e facilitar seu uso no âmbito da Ciência da Informação. Construindo um paralelo entre a trajetória sequencial e militante da análise do discurso na França e seu pouco coerente caminho na América do Norte. Conclui-se com uma abordagem conceitual, histórica e metodológica o espaço de atuação da análise do discurso no âmbito da Ciência da Informação.
\end{abstract}

Keywords: Discurso; Michel Pêcheux; Ciência da Informação; Abordagens metodológicas

\section{Introdução}

A Ciência da Informação, como outras dentre as ciências sociais, considera em vários aspectos, a Análise do Discurso (doravante denominada apenas AD) como uma disciplina que apresenta princípios teóricometodológicos capazes de contribuir para a compreensão e delimitação de campos científicos e sociais, pois é por meio do jogo de enunciados, permeado por posições ideológicas colocadas em jogo no processo histórico-social, que o texto (oral e escrito) é produzido, ou seja, a Ciência da Informação e outras áreas das Ciências Sociais relacionam-se com formações discursivas e formações ideológicas e estão relacionadas ao seu processo de construção histórica.

Assim, propõe-se discutir pressupostos da Análise do Discurso Francesa com vias de ser utilizada enquanto metodologia da pesquisa na Ciência da Informação e Organização do Conhecimento.

Das teorias próximas ao discurso, alguns autores têm sido utilizados e lembrados como fundamentais para a análise dos fenômenos epistemológicos da Ciência da Informação. Michel Foucault, é sempre o mais lembrado por seu grande impacto em todas as Ciências Hu-

\begin{abstract}
Information Science is argued as a theoretical framework as an interdisciplinary field and has its own characteristics and methodologies. The discourse analysis presents theoretical and methodological principles that contribute to understand and delimit scientific and social fields. We aim to present a historical and conceptual background related to the methodological development, seeking to demonstrate ways to delimit and simplify its use in the Information Science field, building a parallel between the sequential trajectory and militant discourse analysis in France and its little consistent path of the French Discourse Analysis in North America. We concluded with a conceptual, historical and methodological definition of discourse analysis in the Information Science range.
\end{abstract}

Keywords2: Discourse; Michel Pêcheux; Information Science; Methodological framework.

manas, contudo, seu papel enquanto teórico do discurso é marginal à sua obra e à teoria do discurso. Ainda, outros autores são lembrados como fundamentais neste percurso, como Jacques Derrida e o seu Mal d'Archive: Une Impression Freudienne, denominados por alguns críticos como pós-modernistas, pós-estruturalistas elou estruturalistas especulativos (Dosse, 1993; Gregolin, 2006). Toda classificação funciona como um simulacro daquilo que ela define. Nesse sentido, a obra de ambos estes autores extrapola qualquer entendimento relacionado a uma determinada corrente filosófica, uma vez que se trata de obras profundamente heterógenas e diversificadas.

Em diferentes níveis, estes autores e outros, estiveram à margem da Ciência da Informação desde o ano 2000, especialmente nos trabalhos que buscavam fugir de perspectivas positivas em território norte americano por uma busca de compreensão diferente das visões "tradicionais" da área, uma vez que as teorias francesas tiveram impacto "retardado" no Canadá e Estados Unidos. Percebe-se Foucault na obra de Frohmann (1992; 1994; 2001, 2004), Campbell (2007) e Derrida na obra de Terry Cook (1997, 2001a, 2001b), Tom Nesmith (2002, 2004), entre outros. 
Contudo, apesar da importância dada a estes dois autores e sua lembrança sempre presente em trabalhos que visam discutir perspectivas anti-positivas, pouco se trabalha estruturalmente e de forma transversal no que se relaciona ao discurso em si, especialmente quando as palavras "análise" e "discurso" aparecem nos títulos, resumos, palavras-chave, etc., de capítulos, livros e periódicos da Organização do Conhecimento e Ciência da Informação.

Principalmente devido ao fato de estes trabalhos serem recentes e estarem em terrenos distantes daqueles que tradicionalmente trabalham com discurso. Países como a França e o Brasil têm discutido discurso e enunciação em ambiente universitário desde a década de 1980, completamente diferente do cenário norte americano em que as teorias da gramática transformacional de Chomsky e Análise Crítica do Discurso, foram mais difundidas e em alguns casos confundida com a análise do discurso francesa.

Assim, dois nomes e duas teorias são sempre esquecidos: Jean Jaques Coutine e Michel Pêcheux, a teoria da enunciação e o materialismo histórico. Visa-se então, trabalhá-los em paralelo aos postulados em relação às formações discursivas e enunciados no âmbito da Ciência da Informação, construindo um paralelo entre a trajetória sequencial e militante da Análise do Discurso na França e o percurso pouco coeso da Análise do Discurso Francesa na América do Norte.

\section{Análise do Discurso Francesa: aspectos históricos e conceituais}

A AD vem modificar a visão estruturante de linguística, visando à compreensão do fenômeno da linguagem não mais centrada apenas na língua, sistema ideologicamente neutro, mas num nível também situado fora do estritamente linguístico.

Por meio da $\mathrm{AD}$, pode-se chegar à conclusão de que nenhum estudo da linguagem pode deixar de levar em conta aspectos da sociedade que a produz, uma vez que os processos que constituem a linguagem são históricosociais.

A linguística, a partir dos anos 60, preocupava-se com a análise de um objeto além da frase, ou seja, começava-se a exigir a abordagem da articulação entre o material linguístico e seu exterior,

Porém, o momento inicial da $\mathrm{AD}$ não é menos importante do que o "último estágio" dessa disciplina, pelo contrário, é o solo sobre o qual se detém para enxergar a construção do edifício teórico.

O território francês para o desenvolvimento da teoria do discurso é bastante diferente daquele que foi apropriado pela Ciência da Informação, para discutir a institucionalização da Informação, aspectos sociais da informação e temáticas relacionadas, ou seja, existe no uso de $\mathrm{AD}$ na $\mathrm{CI}$ um deslocamento e uma naturalização de sua trajetória e de seu percurso.

Gadet (apud Maingueneau, 1997 p.16) ilustra tal diferença entre AD de Pêcheux e Foucault e a AD anglosaxã em um quadro interessante:

\begin{tabular}{|c|c|c|}
\hline & AD Francesa & $A D$ Anglo-saxã \\
\hline $\begin{array}{l}\text { Tipos de dis- } \\
\text { curso }\end{array}$ & $\begin{array}{l}\text { Escrito } \\
\text { Quadro institucional } \\
\text { Doutrinário }\end{array}$ & $\begin{array}{l}\text { Oral } \\
\text { Conversação co- } \\
\text { tidiana } \\
\text { Comum }\end{array}$ \\
\hline $\begin{array}{l}\text { Objetivos de- } \\
\text { terminados }\end{array}$ & $\begin{array}{l}\text { Propósitos textuais } \\
\text { Explicação-forma } \\
\text { Construção do obje- } \\
\text { to } \\
\begin{array}{l}\text { A relação ideolo- } \\
\text { gia/língua }\end{array}\end{array}$ & $\begin{array}{l}\text { Propósitos co- } \\
\text { municacionais } \\
\text { Descrição-uso } \\
\text { Imanência do ob- } \\
\text { jeto }\end{array}$ \\
\hline Método & $\begin{array}{l}\text { Materialismo histó- } \\
\text { rico }\end{array}$ & $\begin{array}{l}\text { Interacionismo } \\
\text { Psicologia e socio- } \\
\text { logia }\end{array}$ \\
\hline Objeto & Linguística & Antropologia \\
\hline
\end{tabular}

Quadro I: Quadro Comparativo entre a AD Francesa e $A D$ Anglo-Saxã. Adaptado de Maingueneau, D.,1997.

Afim de demarcar o espaço de atuação e qual das muitas Análises do Discurso estamos falando, trabalha-se sob a perspectiva Pêcheux-Coutine de AD, na medida em que se busca enunciar que as ciências sociais e as ciências humanas de modo geral, possuem desequilíbrios e inversões regulados pelos sujeitos conscientes, atuantes nas produções textuais e orais, mas também regulados pela ideologia e pelo poder, ou seja, o sentido oculto presente naquele espaço discursivo que ele analisa.

São iniciadas, a partir das considerações de Pêcheux a respeito de Foucault, algumas reformulações da teoria da AAD (Análise Automática de Discurso), especialmente com a formulação de Pêcheux da noção de formação discursiva.

Porém, a contribuição Foucaultiana para a AD é mais periférica, pois, em Foucault, o objeto de estudo é a ciência e sua discursividade; e, em Pêcheux, a AD faz parte de um projeto epistemológico completo, encarada como uma ruptura com os preceitos linguísticos clássicos, e tal posição é pouco discutida ou mesmo desconsiderada por autores como Frohmann, Campbell, dentre outros.

Ainda que a obra de Foucault seja fundamental para a análise, o ator central do projeto é Pêcheux e ele deve ser considerado nas pesquisas que buscam utilizar Análise do Discurso na Ciência da Informação. 
O projeto de análise cresce e constrói-se a partir do seu grupo. Por conta da tradição francesa, as pesquisas ali desenvolvidas centram-se nesta perspectiva. $\mathrm{O}$ mesmo não ocorre na América do Norte.

Ao final da década de 1960, o estruturalismo, anteriormente calcado na linguística, sociologia e antropologia, aproxima-se, em Foucault, da História e com Pêcheux funda-se uma área de interseção, interdisciplinar no mais fundamental do termo.

L'Archeologie du Savoir vem sanar um problema que muitas vezes pode ser percebido nas obras anteriores de Foucault: a ausência de um quadro metodológico explicitado, que vem a ser o objeto de reflexão desta obra.

No núcleo desse quadro, instaura-se a linha de pensamento Foucaultiana de análise do discurso, responsável pela formulação de uma série de conceitos fundamentais para a estruturação metodológica da disciplina, emprestada à AD por Pêcheux a partir de 1975. Discursiva tradicional, presente no método estruturalista, do ideário baseado no marxismo, presente nos seguidores de Althusser.

Contudo, é iniciado um deslocamento, com a formulação de conceitos como a prática discursiva, formação discursiva e formação ideológica.

Para Pêcheux, neste momento, o sujeito do discurso sempre está relacionado entre a posição sujeito da ideologia/sujeito da linguagem, mas o campo de análise é reconfigurado.

Em L'Archeologie du Savoir, Foucault utiliza este método para compreender a "História da História", visando a sua desconstrução. O método que ele utiliza para efetuar tal desconstrução é sua contribuição para a análise do discurso.

Em nenhum caso quis Foucault arvorar-se em defensor de uma positividade qualquer da ciência histórica, por mais nova que fosse. O que lhe interessa é abrir as estruturas para as descontinuidades temporais, para os desequilíbrios e inversões que regulam os deslocamentos de um jogo incessante de práticas discursivas (Dosse, 1994, p.270).

Assim, compreendendo a Ciência da Informação como uma instância significativa e passível desta análise, busca-se no seu passado compreender o atual momento de transição no qual ela se encontra, estabelecendo essa relação arqueológica.

A AD, assim como tantas outras disciplinas desenvolvidas durante o século XX, foi/é uma disciplina permeada por outros campos de conhecimento, no caso, fundamentalmente as Ciências Sociais e a Linguística.

A este respeito, Maldidier (1994, p.19) faz a seguinte avaliação:

(...) A análise do discurso é pensada como ruptura epistemológica com a ideologia que domina nas ciências huma- nas (especialmente a psicologia). O objeto do discurso, que reformula a fala saussuriana na relação com a língua, implica, de acordo com a fórmula althusseriana, uma mudança de terreno. (...) o objeto teórico articula a questão do discurso àquelas do sujeito e da ideologia. A análise (do discurso) só pode ser pensada em relação a uma teoria (do discurso).

O texto fundamental, A propósito da análise automática do discurso: atualização e perspectivas - publicado na revista Langages 37 -, é o resultado de todo o processo de uso da AAD-69 (primeira enunciação da análise do discurso) e atualiza e reestrutura o quadro epistemológico geral na articulação entre o materialismo histórico, a linguística e a teoria discursiva.

Pêcheux e Fuchs (1997, p.163) fazem a seguinte ponderação a respeito dos primeiros momentos da AAD:

Nestes últimos anos, a "análise automática do discurso" (...) produziu um certo número de publicações, tanto no nível teórico quanto no das aplicações experimentais. Parece-nos que as observações, interpretações, críticas ou mesmo deformações suscitadas nestes dois níveis precisam de uma reformulação de conjunto visando a eliminar certas ambiguidades, retificar certos erros, constatar certas dificuldades não-resolvidas e, ao mesmo tempo, indicar as bases para uma nova formulação da questão.

Portanto, esse é o momento das reconsiderações a respeito dos primeiros sete anos da $\mathrm{AD}$, e os autores buscam retificar e renovar algumas abordagens da $\mathrm{AD}$.

A noção de formação discursiva acaba por fazer exatamente isso: deslocar a compreensão da máquina produtora de discursos, desconstruindo-a, uma vez que a Formação Discursiva, em uma relação paradoxal com seu exterior, mais tarde levará a noção de interdiscurso e memória discursiva importante no atual estágio da AD.

Desencadeia-se, assim, a aproximação da AD com a História, atingindo então o seu status consagrado como disciplina de entremeio em uma interseção entre a linguística, a História e a sociologia.

"Diferentemente do intervalo, a ideia de entremeio refere a espaços habitados simultaneamente, estabelecidos por relações contraditórias entre teorias" (Orlandi, 2002, p.1).

Os próprios autores enumeram os entremeios da Análise do discurso:

1. o materialismo histórico, como teoria das formações sociais e de suas transformações, compreendida aí a teoria das ideologias; 2. a linguística, como teoria dos mecanismos sintáticos e dos processos de enunciação ao mesmo tempo; 3 . A teoria do discurso, como teoria da determinação histórica dos processos semânticos. Convém explicitar ainda que estas três regiões são, de certo modo, atravessadas e articuladas por uma teoria da subjetividade (de natureza psicanalítica). (Pêcheu e Fuchs, 1997, p.163-164). 
Baseando-se nesta acepção, é possível perceber o que os autores chamam de quadro epistemológico geral da $\mathrm{AD}$, que lhes dá um status disciplinar mais claro do que aquele presente na ADD-69.

A ideologia, o materialismo histórico e a linguística já estavam presentes na AAD-69. Agora os autores estabelecem a teoria do discurso como uma instância própria desta disciplina de entremeio, cabendo ao analista identificar as relações histórico-ideológicas do discurso. A luta de classes ainda é fundamental para uma análise discursiva, contudo, o efeito de sentido - a relação entre a ideologia e a língua - começa a ser conceituado.

(...) a produção de sentido é estritamente indissociável da relação de paráfrase entre sequência tais que a família parafrástica destas sequências constitui o que se poderia chamar a "matriz do sentido". Isto equivale a dizer que é a partir da relação no interior desta família que se constitui o efeito de sentido, assim como a relação a um referente que implique este efeito (Pêcheux e Fuchs, 1997e, p.169).

Em Foucault, a formação discursiva será parte de seu projeto arqueológico de construir um método que "procura compreender o funcionamento dos discursos que constituem as ciências humanas" (Baronas, 2011, p.92), compreendo-os não como conjunto de signos e elementos dentro de um sistema e de uma estrutura como os estruturalistas trabalhavam, "mas como um conjunto de práticas discursivas que instauram os objetos sobre os quais enunciam, circunscrevem os conceitos, legitimam os sujeitos enunciadores" (op. cit, 2011, p.92).

Nesse sentindo, a Ciência da Informação filia-se a determinadas formações discursivas atravessadas por relações político-ideológicas. Enquanto formação, pode-se dizer que as instituições que legitimam a Ciência da Informação como espaço teórico são filiadas ao estado democrático, à História, à identidade, à um conjunto amplo de instituições e costumes que legitimam e fundamentam seu aparecimento, são elas: as instituições culturais, universidades, museus, centros de documentação, etc.

Portanto, estudar os processos discursivos da Ciência da Informação não pode se basear apenas no biônimo informação-conhecimento, mas no estudo das práticas discursivas que legitimam o aparecimento dessas noções e conceitos.

Essa relação é bem marcada pela própria construção das ciências humanas e sociais, das quais a Ciência da Informação não escapa. É possível dizer, baseando-se em Baronas (2011) e Foucault (1997), que processos discursivos, os quais perpassam os conceitos e objetos da Ciência da Informação, possuem em sua discursividade uma liberdade condicionada, por terem passado pela regulação própria da atividade "política" do discurso das ciências, o que legitima cada um dos discursos efetivamente ditos, determinando como e o que pode ser dito por um sujeito (compreendido com uma posição), com um método aceito, sendo inserido na verdade de uma época.

Dito isso, fica fácil compreender por que, em determinados pontos de "conflito", a área toma rumos em um sentido e não em outro, por que, em determinado contexto, pode-se dizer que as classificações, descrições, indexações, fazem parte de um processamento técnico neutro e imparcial e, em outro, estuda-se e legitima-se uma posição contrária a esse postulado.

Assim, por esses motivos, compreendemos que as formações discursivas das quais a Ciência da Informação faz parte são fruto de e inserem-se em um movimento exterior a elas, mas não o contexto situacional, e sim as condições de produção do discurso, que são permitidas, e determinadas posições e rumos disciplinares.

Segundo Guespin (1971) (apud Charaudeau e Maingueneau, 2004, p.196, grifo nosso):

O enunciado é a sucessão de frases emitidas entres dois bancos semânticos, duas pausas da comunicação; o discurso é o enunciado considerado do ponto de vista do mecanismo discursivo que o condiciona. Assim, olhar um texto sob a perspectiva de sua estruturação "em língua" permite tomá-lo como um enunciado; um estudo linguístico das condições de produção desse texto possibilita considerá-lo um discurso.

A relação simbólica que se estabelece entre o discurso e o enunciado é que permite a análise, à medida que é por meio do enunciado que se constrói a análise, possibilitando assim, a construção de um corpus, visando descrever o conjunto de relações entre os enunciados e formações discursivas.

O método de análise é complexo, pois todos os textos irão remeter a uma pluralidade de formações discursivas. Contudo, conforme nos aproximamos do corpus, começamos a reconhecer alguns padrões de institucionalização discursiva e ideológica e seu papel enquanto instância significativa na atualidade.

Assim, quando estamos falando de $\mathrm{AD}$ nos contextos aqui descritos e da teoria a ela vinculada estamos falando de perspectivas e momentos diferentes daqueles que têm sido trabalhados na América do Norte.

\section{Ciência da Informação e Análise do Discurso: aplicações em seu universo.}

Nesta seção busca-se trabalhar com aspectos metodológicos e de aplicação da AD no âmbito da Ciência da Informação. Para tal, foi necessário dividir o texto em três subseções, duas conceituais e uma aplicada.

\subsection{Discurso e enunciado: partículas para análise}

$\mathrm{Na} \mathrm{AD}$, entende-se o discurso como um espaço aberto, partindo da língua, atravessado pela ideologia e circunscrito por sua própria História. 
Na literatura sobre AD é possível encontrar, atrelado ao conceito de discurso, a metáfora relacionando o discurso com uma rede de sentidos que se transformam em um tecido discursivo. Em Ferreira (2007, p.19), a relação metafórica é assim exposta:

A rede, como um sistema, é um todo organizado, mas não fechado, porque tem os furos, e não estável, porque os sentidos podem passar e chegar por essas brechas a cada momento. Diríamos, então, que um discurso seria uma rede e como tal representaria o todo; só que esse todo comporta em si o não-todo, esse sistema abre lugar para o nãosistêmico e o não-objeto da $\mathrm{AD}$ não é a língua em si ou suas produções, mas o discurso necessita dos elementos linguísticos, o discurso implica uma exterioridade à língua. Ele tem reflexo no texto, mas envolve questões além do linguístico, como foi dito no capítulo anterior, os aspectos ideológicos e sociais a que as palavras remetem quando são escritas ou faladas.

Por isso, pode-se dizer que o discurso é a "palavra em movimento, prática de linguagem" (Orlandi, 2007b p.15).

A AD não irá preocupar-se com o sentido do texto ou mesmo com o sentido do discurso, mas os modos como o texto e o discurso se relacionam na produção de sentidos ao longo do seu percurso histórico, como uma palavra, por exemplo, que irá adquirindo sentidos em uma determinada conjuntura representável.

Segundo Guespin (1971) (apud Charaudeau e Maingueneau, 2004, p.196):

O enunciado é a sucessão de frases emitidas entres dois bancos semânticos, duas pausas da comunicação; o discurso é o enunciado considerado do ponto de vista do mecanismo discursivo que o condiciona. Assim, olhar um texto sob a perspectiva de sua estruturação "em língua" permite tomá-lo como um enunciado; um estudo linguístico das condições de produção desse texto possibilita considerá-lo um discurso.

O enunciado é, portanto, o espaço de inscrição do discurso, a teoria da enunciação nos leva a perceber as estruturas semânticas do texto, já a AD busca colocar o texto em relação a sua memória $e$ seu espaço de inscrição e institucionalização. Assim, o discurso vê o enunciado para além de sua estrutura.

\subsection{A formação discursiva: campo de análise}

A formação discursiva (FD), diferentemente do que é atribuído a Foucault, é uma perspectiva de Courtine (2009), autor que cunhou o conceito. Ele falará, em sua tese, de memória discursiva em uma relação com a interdiscursividade.

Existirá, porém, na produção enunciativo-discursiva, um apagamento e uma distorção, uma vez que aquilo é enunciado.

Existe uma contradição latente ao próprio processo discursivo, o que Pêcheux (2009) chamará de enuncia- do divido, na medida em que, a formação discursiva é perseguida por essa memória.

Orlandi (2007a, p.43) esclarece o funcionamento:

$\mathrm{O}$ discurso se constitui em seus sentidos porque aquilo que o sujeito diz se inscreve em uma formação discursiva e não outra para um sentido e não outro. Por aí podemos perceber que as palavras não têm um sentido nelas mesmas, elas derivam seus sentidos das formações discursivas em que se inscrevem. (...) deste modo, os sentidos sempre são determinados ideologicamente. Não há sentido que não o seja. Tudo que dizemos tem, pois, um traço ideológico em relação a outros traços ideológicos. E isto não está na essência das palavras, mas na discursividade, isto é, na maneira como, no discurso, a ideologia produz seus efeitos, materializando-se nele.

A FD, portanto, é um conceito de conexão entre o enunciado, o sujeito e a ideologia. É o espaço entre o que pode ser dito, devido ao contexto ideológico e político. Este dito, sendo permeado pela ideologia, revela que o sentido não está na palavra, na frase ou no texto, mas acontece na discursividade, partindo da relação entre formação ideológica e formação discursivaenunciado-sujeito.

A formação discursiva é o conjunto de enunciados relacionados a partir de uma posição ideológica, de um lugar real e de sujeitos específicos.

Por exemplo, encara-se aqui a Ciência da Informação como uma inter-relação de formações discursivas.

Encará-la como tal, é perceber que seu conjunto de técnicas, saberes, sujeitos estão relacionados aos enunciados que produzem, e estes enunciados estão relacionados com a conjuntura política e ideológica, com o poder, em um jogo social estabelecido no espaçotempo cheio de conflitos.

Dessa forma, a Ciência da Informação, enquanto um espaço discursivo, nunca está finalizada, é passível de mudanças e possui os apagamentos provocados pela própria ação da ideologia, naturalização destas relações.

Assim, ao encará-la desta maneira, pode-se perceber que os conceitos da disciplina estão sujeitos a um embate externo, que desconstrói e modifica sua prática institucionalizada.

Deve-se acrescentar, ainda, que os conceitos trabalhados na disciplina só são possíveis a partir da posição histórica em que foram construídos, e o significado de um mesmo conceito modifica-se à medida que a posição na formação discursiva se altera ou a filiação ideológica diversifica-se no decorrer do tempo. A FD é a posição do discurso no espaço-tempo.

Palavras iguais podem significar coisas diferentes porque se inscrevem em formações discursivas diferentes, e esta diferença ocorre por que são sujeitos e contextos distintos. 
Cabe, então, ao analista do discurso observar as condições de produção dos textos, e remeter aquele enunciado a uma determinada formação discursiva.

A FD é, portanto, o espaço em que a materialidade enunciativa tem a possibilidade de ser interpretada e compreendida, a partir da posição histórica e ideológica na qual o sujeito encontra-se.

Sobre a FI (Formação Ideológica) em específico, Pêcheux comenta:

Falaremos de formação ideológica para caracterizar um elemento (este aspecto da luta nos aparelhos) suscetível de intervir como uma força em confronto com outras forças, na conjuntura ideológica característica de uma formação social em dado momento; desse modo, cada formação ideológica constitui um conjunto complexo de atitudes e de representações (1997e, p.166).

A Formação Ideológica são os elementos externos à própria formação discursiva, como colocado anteriormente; aquela atravessa e modifica as relações que a esta estabelece no nível político e ideológico.

O conceito atrelado a esta formação é o da ideologia. A ideologia, enquanto conceito, surge primeiramente na obra de Marx e Engels. Para eles, o conceito de ideologia é bastante restritivo por tratar-se de uma crítica ao sistema capitalista e ao pensamento burguês, portanto é o estudo de um fenômeno ideológico e não uma conceituação sobre o comportamento da ideologia enquanto uma noção estrutural das ciências humanas.

A FI é, de modo mais amplo, um conjunto de práticas e atitudes circunscritas no espaço-tempo, que atravessa várias formações discursivas e interliga a rede discursiva.

Pêcheux e Fuchs (1997e, p.167) explicam a FI e sua ligação com as formações discursivas com o seguinte exemplo:

[...] a formação ideológica religiosa constitui, no modo de produção feudal, a forma da ideologia dominante; ela realiza "a interpelação dos indivíduos em sujeitos" através do Aparelho Ideológico do Estado religioso "especializado" nas relações de Deus com os homens, sujeitos de Deus, na forma específica das cerimônias (ofícios, batismos, casamentos, enterros, etc.) que, sob a figura da religião, intervém, em realidade, nas relações jurídicas e na produção econômica, portanto no próprio interior das relações de produção feudais. Na realização destas relações ideológicas de classes, diversas formações discursivas intervêm enquanto componentes combinadas cada vez em formas específicas; por exemplo, e enquanto hipótese histórica a ser verificada: de um lado a pregação camponesa reproduzida pelo "Baixo-Clero" no interior do campesinato, de outro o sermão do alto-clero para os Grandes da nobreza, logo duas formações discursivas [...].

Este exemplo esclarece bem a conceituação da ideologia enquanto FI no interior da teoria do discurso. Existe, no exemplo, uma única FI, a qual permeia outros dois exemplos de FD, mas que, dada a conjuntura apresentada, pode conter um número bem maior de FDs.

Pode-se ainda citar, por exemplo, a própria Ciência da Informação. Como todas as disciplinas, está sujeita aos acontecimentos que a constituem e a institucionalizam, e os embates entre o político, o saber e a ideologia provocam mudanças em sua estrutura discursiva. Analisar o discurso é perceber esses atravessamentos e mostrálos na análise.

Para se analisar um discurso, é necessária a construção de um corpus de análise. "O analista do discurso não é uma pessoa neutra. Nunca. (...) Ele deve, igualmente, construir um observatório para si” (Mazière, 2005, p.23).

3.3 Análise do discurso enquanto metodologia de pesquisa para a Ciência da Informação

Conforme as considerações descritas no item anterior, é possível perceber que a $\mathrm{AD}$ enquanto metodologia de pesquisa trata-se de uma metodologia complexa e que precisa ser aplicada no âmbito de um universo e de um corpus defino.

Portanto, é impossível aplicar análise do discurso, sem fazer justamente isso: analisar o discurso.

Isso significa que é necessário a construção de um corpus de análise, produções textuais efetivas para se operar a análise.

Para citar alguns exemplos interessantes para o universo da ciência da informação e da organização do conhecimento:

1) estudar sobre uma perspectiva discursiva a constituição da ISKO enquanto uma sociedade científica no âmbito da Ciência da Informação, analisando por exemplo as atas plenárias das reuniões da sociedade ou mesmo, os editorias de revistas que trabalham temáticas relacionadas com a organização.

2) pode-se analisar as conversas e discussões que ocorrem nos congressos ISKO, para além das salas de conferências, nos cafés, restaurantes, intervalos... $\mathrm{O}$ discurso fundamenta-se nos espaços que o legitimam.

3) pode-se analisar aspectos condicionantes e profissionais no âmbito de unidades de informação, bibliotecas universitárias em relação a bibliotecas escolares, as bibliotecas à margem dessa relação, como as populares, comunitárias, ambulantes.

O mesmo é possível no universo dos arquivos, analisando aspectos relacionados a opacidade ideológica dessas instituições nas várias esferas de atuação.

Analisar discurso pressupõe tomar partido e fundamenta-se no aprofundamento do discurso estudado. Coisa que pouco foi explorada no universo da Ciência da Informação e se o foi, foi explorada de forma deslocada e naturalizada. 
Aspectos conceituais e históricos são fundamentais, porém, por meio desses não se enxerga para além do horizonte do próprio "laboratório", é preciso ir além.

Os estudos descritos quando da introdução deste artigo, foram fundamentais para possibilitar pontes de aproximações com a perspectiva do discurso, porém são necessários novos estudos e novas abordagens ao discurso.

A medida que este estudo avançar, busca-se analisar aspectos qualitativos e quantitativos dos possíveis usos da AD no âmbito da CI.

Este trabalho trata-se de um estudo inicial, quase que um estado da arte da AD enquanto teoria e metodologia de abordagem.

A partir daqui se buscará aprofundar-se em aspectos num primeiro momento quantitativos, da relação entre os dois campos e posteriormente qualitativos, ou seja, em que sentido realmente deve-se apropriar dos estudos do discurso na Ciência da Informação.

\section{Considerações Finais}

Buscou-se neste artigo apresentar e conceituar noções fundamentais da Análise do Discurso em relação à sua história e memória, afim de demarcar um espaço de atuação para a Ciência da Informação.

Discutiu-se os principais autores que contribuíram para o aparecimento e criação da $\mathrm{AD}$ enquanto um campo interdisciplinar de estudo.

Destacou-se também dois nomes entendidos como fundamentais, mas pouco estudados no contexto da Ciência da Informação. Jean Jaques Coutine e Michel Pêcheux, a teoria da enunciação e o materialismo trabalhados em paralelo com a própria mitologia do discurso e a sua aplicação.

Desse modo, apresentou-se histórico-conceitualmente como a Análise do Discurso se desenvolveu e as formas de abordagem do discurso possíveis à Ciência da Informação. Quer em relação a sua episteme, quer em relação às abordagens metodológicas, buscando facilitar e demarcar seu uso

Construiu-se um paralelo entre a trajetória sequencial e militante da Análise do Discurso na França bastante diferente do recorrente e atual uso de Análise do Discurso por parte de teóricos na América do Norte.

Fundamentalmente, estudos interdisciplinares são recorrentes e importantes no âmbito da Ciência da Informação. Porém, é necessário o aprofundamento do estudo dessas relações e metodologias interdisciplinares. Só desta forma é que será possível o uso e aplicação de AD no universo teórico da Ciência da Informação e Organização do Conhecimento.

\section{Notas}

(1) (...) determinam o que pode e deve ser dito (articulado sob a forma de uma arenga, um sermão, um panfleto, uma exposição, um programa etc.) a partir de uma posição dada numa conjuntura, isto é, numa certa relação de lugares no interior de um aparelho ideológico, e inscrita numa relação de classes (Pêcheux e Fuchs, 1997, p.166-167).

(2) Guespin, L. Problematique des travaux sur le discours politique. // Langages, 23 (1971) p.3-24.

\section{Referências}

Baronas, R. L. (2011). Ensaios em análise do discurso: questões analítico-teóricas. EdUFScar, São Carlos, 2011

Campbell, D. G. (2007). The Birth of the New Web: A Foucauldian Reading of the Semantic Web. // Cataloging \& Classification Quarterly 43:3 (2011) 9-20.

Cook, T. (1997). What is past is prologue: a history of archival ideas since 1898, and the future paradigm shift. // Archivaria 43:3 (1997)18-63.

Cook, T. (2001a). Fashionable Nonsense or professional rebirth postmodernism and practices of archives. // Archivaria 51:3 (2001a) 14-35

Cook, T. (2001b). Archival science and postmodernism: new formulations for old concepts. // Archival Science 1:1 (2001b) 3-24

Charaudeau, P.; Maingueneau, D. (2004) Dicionário de análise do discurso. Contexto, Campinas, 2004

Dosse, F. (1993) História do estruturalismo. Ed da Unicamp, Campinas, 1993, 1v.

Dosse, F. (1994) História do estruturalismo. Ed da Unicamp, Campinas, 1994, 2v.

Ferreira, M.C.L. (2007) O quadro atual da análise do discurso no Brasil um breve perâmbulo // Ferreira, M.C.L.; Indursky, F. (eds.). Michel Pêcheux e Análise do discurso: uma relação de nunca acabar. São Carlos: Claraluz, 2007. 13-22.

Foucault, M. 1997. A arqueologia do saber. Forense, Rio de janeiro, 1997.

Frohmann, B. (1992). The Power of Images: A Discourse Analysis of the Cognitive Viewpoint. //Journal of Documentation 48:4 (1992) 365-86

Frohmann, B. (1994). Discourse Analysis as a Research Method in Library and Information Science. // Library and Information Science Research 16:1 (1994) 19-38.

Frohmann, B. (2001). Discourse and Documentation: Some Implications for Pedagogy and Research. //Journal of Education for Library \& Information Science 42:1 (2001) 13-26.

Frohmann, B. (2004). Deflating Information: From Science Studies to Documentation University of Toronto Press, Toronto, 2004.

Gregolin, M. R. (2006). Foucault e Pêcheux: na análise do discurso diálogos \& duelos. Ed Claraluz, São Carlos, 2006.

Maingueneau, D. (1997). Novas tendências em análise do discurso. Pontes, Campinas, 1997.

Maldidier, D. (1994a). Elementos para uma História da Análise do discurso na França. // Orlandi, E.P. Gestos de Leitura: da História no discurso. Campinas: Ed. da Unicamp, 15-28.

Mazière, F. (2005). L'Analyse du Discours. Presses Universitaires de France, Paris, 2005. 
Nesmith, T. (2002). Seeing Archives: Postmodernism and the Changing Intellectual Place of Archives. //American Archivist 50:2 (2002) 90-132.

Nesmith, T. (2004). What's History Got to Do With It?: Reconsidering the Place of Historical Knowledge in Archival Work. // Archivaria, 57:2 (2004) 200-240.

Guespin, L. (1971). Problematique des travaux sur le discuourse politique // Langages 23 (1971) 3-24.

Orlandi, E.P. (2007a). A análise do discurso em suas diferentes tradições intelectuais: O Brasil. // Ferreira, M.C.L.; Indursky, F. (eds.). Michel Pêcheux e Análise do discurso: uma relação de nunca acabar. 2.ed. São Carlos: Claraluz, 75-88.

Orlandi, E.P. (2007b). Análise de discurso: princípios e procedimentos Pontes, Campinas, 2007.

Orlandi, E.P. (2002). A análise de discurso e seus entremeios: notas a sua História no Brasil. // Caderno de Estudos Linguísticos 42:1 (2002) 21-40.

Orlandi, E.P. (2009). Claude Lévi-Strauss, Michel Pêcheux e o estruturalismo. // ComCiência 108:1 (2009) 1-3.

Pêcheux, M.; Fuchs, C. A propósito da análise automática do discurso: atualização e perspectivas (1975). // Gadet, F.; Hak, T. Por uma análise automática do discurso: uma introdução à obra de Michel Pêcheux. Campinas: Editora da Unicamp, 1997. 163252 .

Pêcheux, M. (2009) O estranho espelho da análise do discurso. // Courtine, J-J. (org). Análise do discurso politico: o discurso comunista endereçado aos cristãos. São Calors: EDUFScar, 2009. 90-110.

Copyright: () 2017. Barros. This is an open-access article distributed under the terms of the Creative Commons CC Attribution-ShareAlike (CC BY-SA), which permits use, distribution, and reproduction in any medium, under the identical terms, and provided the original author and source are credited.

Received: 2017-01-30 Accepted: 2017-05-05 